\title{
Progress in Nurturing Human Well-Being
}

\author{
Anthony Biglan ${ }^{1} \cdot$ Ronald Prinz ${ }^{2}$
}

Published online: 8 March 2017

(c) Springer Science+Business Media New York 2017

\begin{abstract}
Substantial evidence in the behavioral and social sciences has accrued in support of numerous intervention programs and policies bearing on improving the lives of children and families. To this end, Clinical Child and Family Psychology Review features a special journal issue on "Evolving Toward a More Nurturing Society." The field has achieved numerous advances regarding how to create and promote nurturing environments that foster successful development and prevent psychological and behavioral problems in children and youth. Such advances cut across multiple strategies (e.g., programs and interventions, practices, and public policies), settings (e.g., family, school including preschool and K-12, service sectors, community), domains (e.g., behavioral health, parenting, cognitive and academic functioning, nutrition, physical activity, obesity, safety, and many other domains), and developmental periods of childhood. The special journal issue showcases a sampling of strategies and domains relevant to producing optimal conditions of nurturance for children and families.
\end{abstract}

Keywords Nurturing environment · Population health · Evidence-based parenting support $\cdot$ Child well-being

This article introduces a special journal issue in Clinical Child and Family Psychology Review on "Evolving Toward a More Nurturing Society." The premise underlying this

Ronald Prinz

prinz@mailbox.sc.edu

1 Oregon Research Institute, Eugene, OR 97403, USA

2 Parenting and Family Research Center, Psychology Department, University of South Carolina, Columbia, SC 29208, USA special issue is that substantial evidence in the behavioral and social sciences has accrued in support of numerous intervention programs and policies bearing on improving the lives of children and families.

It is easy to overlook how much progress the behavioral sciences have made. Most scientists specialize in fairly narrow areas of study because that division of labor is most productive. As a result even many behavioral scientists might not realize how much progress has been made. And those outside the behavioral and social sciences are even less likely to be aware of our progress. But over the last 50 years it is fair to say that the behavioral and social sciences have made more progress in understanding human behavior than occurred in the previous 1000 years. We have identified the major influences on psychological and behavioral problems and have made significant progress in understanding how social determinants influence these problems as well as physical health. More importantly, behavioral scientists have identified a wide range of family, school, and community interventions, as well as policies, that have proven beneficial in increasing the proportion of the population experiencing healthy, productive, and caring lives.

Undoubtedly, the concept of a nurturing environment though simple in words is multidimensional and intricate in nature and application. A useful framework put forth by Biglan et al. (2012) defines a nurturing environment for children and youth as one that fosters successful development and prevents psychological and behavioral problems. This framework postulates that nurturing environments reflect four operating principles: (1) minimization of biologically and psychologically toxic events and conditions; (2) teaching, promotion, and frequent reinforcement of prosocial behavior (including the many skills and self-regulatory behaviors needed to become productive adults); (3) 
monitoring and limiting the influences and opportunities for problem behavior; and, (4) promotion of flexibility and pragmatic thinking that permits the embracing of pro-sociality (Biglan 2015; Biglan et al. 2012).

The impetus for this special issue is that there have been numerous and significant advances regarding the contributions of the behavioral and social sciences to nurturing environments. Such advances cut across multiple strategies (e.g., programs and interventions, practices, and public policies), settings (e.g., family, school including preschool and K-12, service sectors, community), domains (e.g., behavioral health, parenting, cognitive and academic functioning, nutrition, physical activity, obesity, safety, and many other domains), and developmental periods of childhood. The topics covered in the articles for this special issue represent only a sampling of strategies and domains relevant to producing optimal conditions of nurturance for children and families. The articles address: (1) public health intervention to strengthen the acquisition of language and emergent literacy in young children; (2) broad implementation of effective practices to increase pro-sociality in schools; (3) dissemination of evidence-based parenting support as a population health strategy; (4) prevention of obesity in children and adolescents; (5) policies pertaining to family economic security that can and do contribute to child and family health; and, (6) application of cogent policies and procedures in child welfare systems to bring about better outcomes for children caught up in those systems.

The ultimate benefit of our work can be measured by the proportion of the population that is living long and productive lives. A number of the articles showcase how advances of the past four decades are being translated into improvements in the well-being of entire populations. The nature of this approach to prevention provides an important opportunity to develop much needed models for economic modeling and analysis to understand the potential benefits relative to the investment costs in the context of population-wide promotion of child well-being.

Beyond the examples found in this special issue, there are many other areas of progress and need relative to the promotion of nurturing environments positively impacting child well-being (Mick et al. 2012). Pertinent research and strategies are emerging in areas such as the reduction of bullying (Bradshaw 2015), the prevention of child abuse (Prinz 2016), the strengthening of emotional and behavioral self-regulation (Greenberg and Lippold 2013; Sanders and Mazzucchelli 2013), and the promotion of kindness and compassion in children and adults (Ponischil 2014). We hope that the kinds of applications exemplified in this special issue will further advance the efforts of scientists from many disciplines to translate what we have been learning into increases in the well-being of entire populations. Science has changed the world massively over the past 200 years — often for the better and sometimes for the worse. But its most important contribution might yet be the development of societies that nurture the well-being of every person.

\section{References}

Biglan, A. (2015). The nurture effect: How the science of human behavior can improve our lives and our world. Oakland, CA: New Harbinger Publications.

Biglan, A., Flay, B. R., Embry, D. D., \& Sandler, I. (2012). Nurturing environments and the next generation of prevention research and practice. American Psychologist, 67, 257-271. doi:10.1037/ a0026796.

Bradshaw, C. P. (2015). Translating research to practice in bullying prevention. American Psychologist, 70, 322-332. doi:10.1037/ a0039114.

Greenberg, M. T., \& Lippold, M. A. (2013). Promoting healthy outcomes among youth with multiple risks: Innovative approaches. Annual Review of Public Health, 34, 253-270. doi:10.1146/annurev-pubhealth-0318111-24619.

Mick, D., Pettigrew, S., Pechmann, C., \& Ozanne, J. (2012). Transformative consumer research for personal and collective well-being. New York: Taylor \& Francis.

Ponischil, K. (2014). Cultivating kindness and compassion in children. https://depts.washington.edu/ccfwb/content/cultivat ing-kindness-and-compassion-children-0.

Prinz, R. J. (2016). Parenting and family support within a broad child abuse prevention strategy. Child Abuse and Neglect, 51, 400-406. doi:10.1016/j.chiabu.2015.10.015.

Sanders, M. R., \& Mazzucchelli, T. G. (2013). The promotion of selfregulation through parenting interventions. Clinical Child and Family Psychology Review, 16, 1-17. doi:10.1007/s105670130129. 